\title{
High-Rate Moving-Bed Biofilm Anaerobic Digestion for Waste Activated Sludge Treatment
}

\author{
NGO Van Anh*, VUONG Thi Huyen*, LE Van Chieu**, NGUYEN Thi Ha***, Mitsuharu \\ TERASHIMA*, Hidenari YASUI* \\ *Faculty of Environmental Engineering, the University of Kitakyushu, 1-1 Hibikino, \\ Wakamatsu, Kitakyushu 808-0135, Japan \\ **Research Center for Environmental Technology and Sustainable Development, VNU \\ University of Science, 334 Nguyen Trai Street, Thanh Xuan District, Hanoi 10000, Vietnam \\ ***Faculty of Environmental Science, VNU University of Science, 334 Nguyen Trai Street, \\ Thanh Xuan District, Hanoi 10000, Vietnam
}

\begin{abstract}
In a mesophilic anaerobic digestion process, decayed waste activated sludge biomass fed to a digester formed soluble COD substrates, which were eventually converted to methane by anaerobic microorganisms. To improve the decomposition of the soluble materials, performance of a high-rate anaerobic digester was experimentally evaluated. A lab-scale moving-bed biofilm digester having $83.33 \mathrm{~m}^{2}$-carrier surface $/ \mathrm{m}^{3}$-reactor was operated for 200 days with decreasing HRT from 20 days to 1 day, while comparing its response to a conventional chemostat digester. Although both reactors gave a comparable methane production until a 15-day HRT, the soluble TOC in the chemostat digester elevated to $3,000 \mathrm{mg} / \mathrm{L}$ at 4-day HRT suggesting washout of the anaerobic microorganisms. On the other hand, the moving-bed biofilm digester kept a reasonable methane production rate without accumulation of the soluble materials until 3-day HRT. When the HRT was reduced to 2 days, the soluble fraction decreased due to limited production of the decayed materials. To simulate the responses, an extended IWA-Activated Sludge Model was applied and individual kinetics were estimated. The simulation demonstrated that the relevant active anaerobic biomass (acidogens and methanogens) accumulated in the moving-bed biofilm digester showing high TVS digestion efficiency $(25 \%)$ at even very short HRT.
\end{abstract}

Keywords: environmental modeling, wastewater treatment, water purification, water quality

\section{INTRODUCTION}

Anaerobic digestion of waste activated sludge (WAS) is a system wherein microorganisms in the WAS are anaerobically decomposed into inert particulates and biodegradable material giving methane and carbon dioxide as end-products. Although this system has been widely applied to the reduction of WAS in municipal wastewater treatment plants (WWTPs), its long reaction time of $15-25$ days has also pointed out to be an essential research topic for the improvement of system performance (Appels et al., 2008). Apart from slow-growing methanogens Yasui et al. (2006) demonstrated that the anaerobic decay of heterotrophic organisms $\left(\mathrm{X}_{\mathrm{OHO}}\right)$ in WAS governed the entire digestion rate in the digester as long as the acidogenic and methanogenic biomass were reasonably kept. Therefore, to realize high-rate digestion system, application of a moving-bed process to the anaerobic digestion process would be an interesting option since relevant slow-growing microorganisms may grow and retain in the biofilm at the moving-bed carrier media. Based on this expectation, a study was formulated to develop a mathematical model depicting the biological reactions occurring in the systems that could simulate the dynamic responses.

\footnotetext{
Address correspondence to Hidenari Yasui, Faculty of Environmental Engineering, The University of Kitakyushu, Email: hidenari-yasui@kitakyu-u.ac.jp Received May 23, 2014, Accepted August 8, 2014.
} 
The model developed was a modification of the Anaerobic Digestion Model No.1 (ADM1) (Batstone et al., 2002) and the Activated Sludge Model 1 (ASM1) (Henze et al., 2000) which were presented by task groups at International Water Association (IWA) and some of the most implemented mathematical models in many sectors. The degradation of organic compounds is assumed to be divided into the following steps in ADM1: (1) disintegration of homogenous particles to carbohydrates, proteins and lipids, (2) hydrolysis of the complex organic molecules to monomers as sugars, amino acids and long-chain fatty acids, (3) acidogenesis, (4) acetogenesis and (5) methanogenesis. Acidogenesis and acetogenesis include the dynamics of the volatile fatty acids (VFAs) acetate, propionate, butyrate and valerate. Ultimately, acetate and hydrogen compounds are utilized by the methanogens and converted into methane. On the other hand ASM1 describes an activated sludge system with organic oxidation, nitrification and denitrification. The organic material in ASM1 is divided into biodegradable COD and non-biodegradable COD (inert material $\left(\mathrm{X}_{\mathrm{U}}\right)$ ) which are partly produced from the biomass decay with fixed stoichiometry. The biodegradable COD is further divided into active biomass, readily soluble biodegradable substrate $\left(\mathrm{S}_{\mathrm{B}}\right)$ and slowly hydrolysable materials $\left(\mathrm{XC}_{\mathrm{B}}\right)$ that eventually becomes $\mathrm{S}_{\mathrm{B}}$ (Corominas et al., 2010). To reduce the complexity on ADM1 structure it was decided to use ASM1 as a platform of the development with adding essential reactions in ADM1, since the structure of ASM1 was thought to be the main contributor to the production of new biomass and removal of COD. This model would allow to simulate the variation of total volatile solid (TVS) digestion efficiency (ratio of decomposed material to the amount fed), methane production rate (MPR) and soluble total organic concentration (S-TOC) in the digesters.

\section{MATERIALS AND METHODS}

Estimation of organic particulate constituents and specific decay rate of the heterotrophic biomass in the activated sludge

The fresh WAS was collected for 100 days at a regular interval of 2 weeks from Kogasaki WWTP, Kitakyushu, Japan, operated at about 5-day sludge retention time (SRT). The samples were then transferred to an incubation vessel of $500 \mathrm{~mL}$ working volume with the addition of $20 \mathrm{mg} / \mathrm{L}$ of allylthiourea (Tokyo Chemical Industry, Japan) to suppress oxygen uptake by nitrifiers for the aerobic batch tests. The percentages of individual ASM-based WAS constituents (ordinary heterotrophs $\left(\mathrm{X}_{\mathrm{OHO}}\right)$, slowly hydrolysable materials $\left(\mathrm{XC}_{\mathrm{B}}\right)$ and non-biodegradable particulate $\left(\mathrm{X}_{\mathrm{U}}\right)$ ) were estimated focusing on the chronological response of oxygen uptake rate (OUR) that was mostly attributed to the decay of $\mathrm{X}_{\mathrm{OHO}}$. The OUR was logged every 10 minutes for $5-7$ days using a respirometer with an automatic oxygen gas supply system provided by Challenging Systems Inc, USA (AER-8). For the anaerobic tests, anaerobically digested sludge for seed was simultaneously taken from a mesophilic digester at Hiagari WWTP, Kitakyushu, Japan, receiving $30.8 \mathrm{~kg} / \mathrm{m}^{3}$ of primary sludge and $43.9 \mathrm{~kg} / \mathrm{m}^{3}$ of WAS at 36 - 41-day HRT, and its $450 \mathrm{~mL}$ was mixed with $50 \mathrm{~mL}$ of the WAS. Nitrogen gas was purged before sealing the incubation vessels and MPR was logged every 30 minutes using a respirometer without supplying oxygen. Based on the MPR response, the specific decay rate of $\mathrm{X}_{\mathrm{OHO}}$ in the anaerobic condition was estimated. The average specific decay rates $\left(0.15 \mathrm{~d}^{-1}\right)$ was used for the dynamic simulation in the continuous experiments. 


\section{Continuous anaerobic digestion test}

A lab-scale continuous moving-bed biofilm digester (MD) (filled with short plastic tube with $15 \mathrm{~mm}$ height and $15 \mathrm{~mm}$ diameter corresponding to $83.33 \mathrm{~m}^{2}$-carrier surface $/ \mathrm{m}^{3}$-reactor) was operated at $35 \pm 2{ }^{\circ} \mathrm{C}$ with a working volume of 8 liters and stirring speed of $70 \mathrm{rpm}$ while a control digester (CD) with a working volume of 1 liter was also simultaneously operated under chemostat mode with an identical condition except the addition of the carrier media (Fig. 1). Anaerobic inoculum was collected from the mesophilic digester at Hiagari WWTP, Kitakyushu, Japan. The fresh WAS was collected at about 1 - 7-day intervals from Kogasaki WWTP, Kitakyushu, Japan, and stored at $4{ }^{\circ} \mathrm{C}$. The sludge was fed daily to the two digesters while decreasing the HRT from 20 days to 1 day in a step-wise manner. The methane gas production from the digesters was continuously logged using a gas counter after passing it through caustic pellets to remove $\mathrm{CO}_{2}$ in the biogas (MGC-1, Litre Meter Limited, UK).

\section{Analytical procedures}

Total solid (TS), total volatile solid (TVS), chemical oxygen demand (COD) and soluble organic carbon (S-TOC) concentrations were measured according to Standard Methods, $21^{\text {st }}$ edition (APHA, 2005). The soluble COD concentration was approximated from the measured S-TOC with a stoichiometric factor of $2.67(=32 / 12)$, which was deduced from typical WAS elemental constituents $\left(\mathrm{C}_{5} \mathrm{H}_{7} \mathrm{O}_{2} \mathrm{~N}\right)$.

\section{Dynamic simulation}

The dynamic simulations of the two continuous experiments were performed focusing on responses of the methane production, soluble and particulate concentrations obtained from the COD in the digesters. The system responses were simulated using GPS-X ver. 6.2 (Hydromantis Environmental Software Solutions Inc., Canada). The simulation layout for the two digesters are shown in Fig. 2. To express the concentrated biomass in the moving bed digester, a solid-liquid separator was customized to entrap the relevant state variables in the system (e.g. acidogens and methanogens in the system). Although diffusion resistance of soluble substrates in the biofilm was not incorporated in the model, it was thought that the impact would be limited in the anaerobic digester because the entire reaction was mostly governed by the decomposition of particulates. For simulating the responses of the individual state variables and digestion performances, an extended Activated Sludge Model 1 (ASM1) was applied as shown in Table 1 and Table 2 (Yasui et al., 2006).

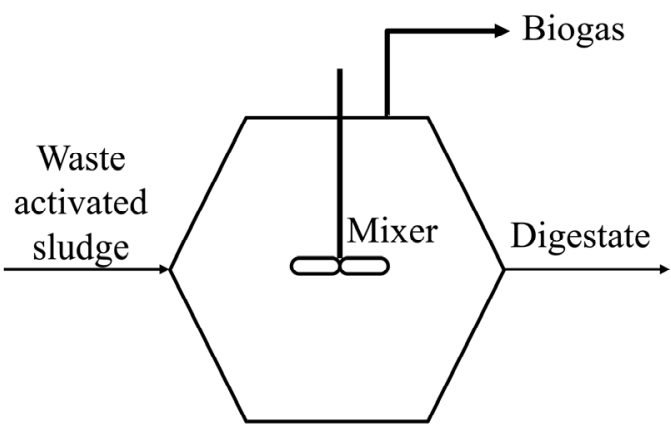

(a)

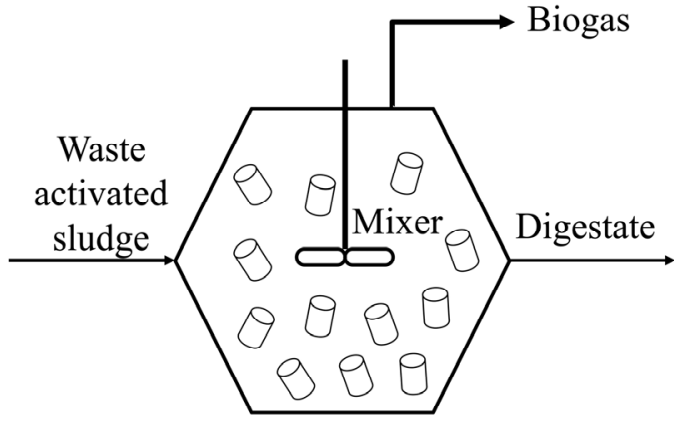

(b)

Fig. 1 - Continuous anaerobic digesters (a): control digester (CD); (b): moving-bed biofilm digester (MD). 
Waste activated sludge Moving-bed biofilm Digester Entrapment of biomass Digestate
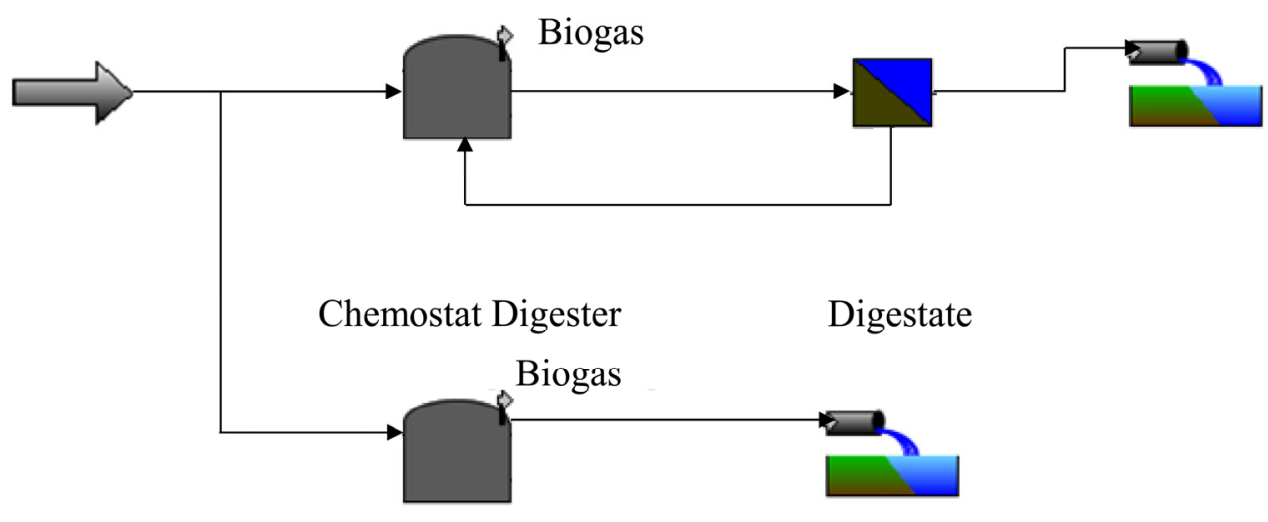

Fig. 2 - Simulation layout of the digesters.

Table 1 - Gujer matrix of the extended ASM1.

\begin{tabular}{|c|c|c|c|c|c|c|c|c|}
\hline Process & Description & $\mathrm{X}_{\mathrm{U}}$ & $\mathrm{X}_{\mathrm{OHO}}$ & $\mathrm{X}_{\mathrm{ACO}}$ & $\mathrm{X}_{\mathrm{MEO}}$ & $\mathrm{XC}_{\mathrm{B}}$ & $\mathrm{S}_{\mathrm{B}, \mathrm{MEO}}$ & $\mathrm{S}_{\mathrm{CH} 4}$ \\
\hline $\mathrm{r} 1$ & $\begin{array}{c}\text { Decay of } \\
\text { methanogens }\end{array}$ & $f_{U}$ & & & -1 & $1-f_{U}$ & & \\
\hline r2 & $\begin{array}{c}\text { Growth of } \\
\text { methanogens }\end{array}$ & & & & +1 & & $-1 / \mathrm{Y}_{\mathrm{MEO}}$ & $\left(1 / \mathrm{Y}_{\mathrm{MEO}}\right)-1$ \\
\hline r3 & Decay of acidogens & $f_{U}$ & & -1 & & $1-f_{U}$ & & \\
\hline $\mathrm{r} 4$ & Growth of acidogens & & & +1 & & $-1 / \mathrm{Y}_{\mathrm{ACO}}$ & $1 / \mathrm{Y}_{\mathrm{ACO}^{-}} 1$ & \\
\hline r5 & $\begin{array}{c}\text { Decay of } \\
\text { heterotrophs }\end{array}$ & $f_{U}$ & -1 & & & $1-f_{U}$ & & \\
\hline
\end{tabular}

$\mathrm{X}_{\mathrm{U}}$ : non-biodegradable particulate $\left(\mathrm{g}-\mathrm{COD} / \mathrm{m}^{3}\right), \mathrm{X}_{\mathrm{OHO}}$ : ordinary heterotrophs in WAS $\left(\mathrm{g}-\mathrm{COD} / \mathrm{m}^{3}\right), \mathrm{X}_{\mathrm{ACO}}$ : acidogens $\left(\mathrm{g}-\mathrm{COD} / \mathrm{m}^{3}\right), \mathrm{X}_{\mathrm{MEO}}$ : methanogens $\left(\mathrm{g}-\mathrm{COD} / \mathrm{m}^{3}\right), \mathrm{XC}_{\mathrm{B}}$ : slowly hydrolysable materials for acidogens $\left(\mathrm{g}-\mathrm{COD} / \mathrm{m}^{3}\right), \mathrm{S}_{\mathrm{B}, \mathrm{MEO}}$ : substrate for methanogens $\left(\mathrm{g}-\mathrm{COD} / \mathrm{m}^{3}\right), \mathrm{S}_{\mathrm{CH} 4}$ : methane $\left(\right.$ mole- $\left.\mathrm{CH}_{4} / \mathrm{L}\right), \mathrm{f}_{\mathrm{U}}$ : Production of inert materials (-), $\mathrm{Y}_{\mathrm{ACO}}$ : Yield of $\mathrm{X}_{\mathrm{ACO}}(-)$; $\mathrm{Y}_{\mathrm{MEO}}$ : Yield of $\mathrm{X}_{\mathrm{MEO}}(-)$

Table 2 - Process rate equations of the extended ASM1.

\begin{tabular}{|c|c|c|c|c|}
\hline Process & Description & \multicolumn{3}{|c|}{ Process rate equations } \\
\hline r1 & $\begin{array}{c}\text { Decay of } \\
\text { methanogens }\end{array}$ & \multicolumn{3}{|c|}{$\mathrm{b}_{\mathrm{MEO}} \cdot \mathrm{X}_{\mathrm{MEO}}$} \\
\hline \multirow{2}{*}{$\mathrm{r} 2$} & \multirow{2}{*}{$\begin{array}{c}\text { Growth of } \\
\text { methanogens }\end{array}$} & \multirow{2}{*}{$\mu_{\max \_\mathrm{MEO}}$} & $\mathrm{S}_{\mathrm{B}, \mathrm{MEO}}$ & \multirow{2}{*}{$\cdot \mathrm{X}_{\mathrm{MEO}}$} \\
\hline & & & $\mathrm{K}_{\mathrm{S}, \mathrm{MEO}}+\mathrm{S}_{\mathrm{B}, \mathrm{MEO}}$ & \\
\hline r3 & Decay of acidogens & & $\mathrm{b}_{\mathrm{ACO}} \cdot \mathrm{X}_{\mathrm{ACO}}$ & \\
\hline & & & $\mathrm{XC}_{\mathrm{B}}$ & \\
\hline r4 & Growth of acidogens & $\mu_{\max \_\mathrm{ACO}}$ & $\overline{\mathrm{K}_{\mathrm{S}, \mathrm{ACO}}+\mathrm{XC}_{\mathrm{B}}}$ & $\cdot \mathrm{X}_{\mathrm{ACO}}$ \\
\hline r5 & $\begin{array}{c}\text { Decay of } \\
\text { heterotrophs }\end{array}$ & & $\mathrm{b}_{\mathrm{OHO}} \cdot \mathrm{X}_{\mathrm{OHO}}$ & \\
\hline
\end{tabular}

$\mathrm{b}_{\text {MEO }}$ : Specific decay rate of methanogens $\left(\mathrm{d}^{-1}\right), \mathrm{b}_{\mathrm{ACO}}$ : Specific decay rate of acidogens $\left(\mathrm{d}^{-1}\right), \mathrm{b}_{\mathrm{OHO}}$ : Specific decay rate of heterotrophs $\left(\mathrm{d}^{-1}\right), \mu_{\max \text { MEO }}$ : Maximum specific growth rate of methanogens $\left(\mathrm{d}^{-1}\right)$, $\mu_{\text {max } A C O}$ : Maximum specific growth rate of acidogens $\left(\mathrm{d}^{-1}\right), \mathrm{K}_{\mathrm{S}, \mathrm{MEO}}$ : half-saturation substrate coefficient on growth of methanogens $\left(\mathrm{g}-\mathrm{COD} / \mathrm{m}^{3}\right), \mathrm{K}_{\mathrm{S}, \mathrm{ACO}}$ : half-saturation substrate coefficient on growth of acidogens $\left(\mathrm{g}-\mathrm{COD} / \mathrm{m}^{3}\right)$ 


\section{RESULTS AND DISCUSSION}

\section{Compositions of the waste activated sludge}

The fed WAS constituents and the volumetric loading rates (VLRs) in the continuous experiment over 200 days were summarized in Fig. 3. Since the WAS was collected on different days, the concentration of WAS thickened at the laboratory slightly varied and VLR was changed accordingly. Corresponding to the decrease of hydraulic retention time (HRT), the VLRs elevated from 1 to $10.4 \mathrm{~kg}-\mathrm{COD} / \mathrm{m}^{3} / \mathrm{d}$ except that there was no feeding of WAS on day 179. According to the batch tests under aerobic and anaerobic conditions, $\mathrm{X}_{\mathrm{OHO}}$ fraction in WAS during the experimental period was estimated to be $33-52 \%$ while $4-17 \%$ of $\mathrm{XC}_{\mathrm{B}}$ (intermediate from the partially decayed biomass $\approx$ $\mathrm{S}_{\mathrm{S}, \mathrm{ACO}}$ ) were detected in the WAS.

\section{TVS digestion efficiency and decomposition of particulate COD}

The trend of TVS digestion efficiency and particulate COD concentration (P-COD) in the digesters were plotted as shown in Fig. 4. The two digesters showed comparable responses for both P-COD concentration and TVS digestion efficiency until day 150 $(\mathrm{HRT}=20,15,10$-day) whereas a maximum of $40 \%$ of digestion efficiency was observed at 20-day HRT. When the HRT was reduced to 5 days, a divergence in the TVS digestion efficiency of the two digesters was recognized. The divergence became larger when the HRT was reduced to 1 day. In the operating condition, TVS digestion efficiency in the CD declined sharply from 30 to $10 \%$ whereas TVS digestion efficiency in the MD decreased only until $25 \%$. The deterioration of TVS digestion efficiency for the $C D$ was thought to be due to a washout of active anaerobic biomass. Since the digestion efficiency at the MD did not change significantly in the operating conditions, it seemed that the presence of carrier media could give a positive effect on the anaerobic digestion. The responses of the P-COD concentration in the two digesters, which corresponded to their TVS digestion efficiency, had fluctuation over the experimental period due to fluctuation of fed WAS concentration. Nevertheless, the change in P-COD concentration could be well reproduced using the simplified mathematical model.

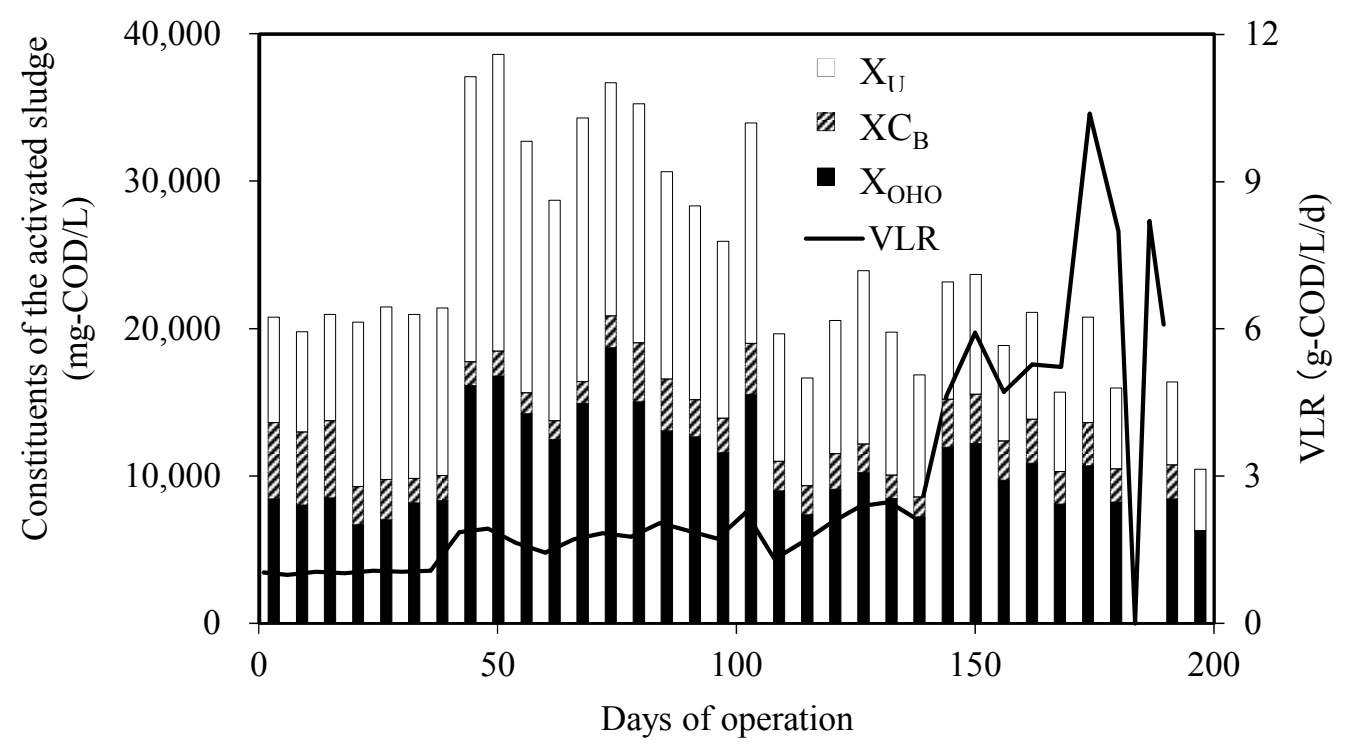

Fig. 3 - Constituents of the fed WAS and volumetric loading rate to the digesters. 


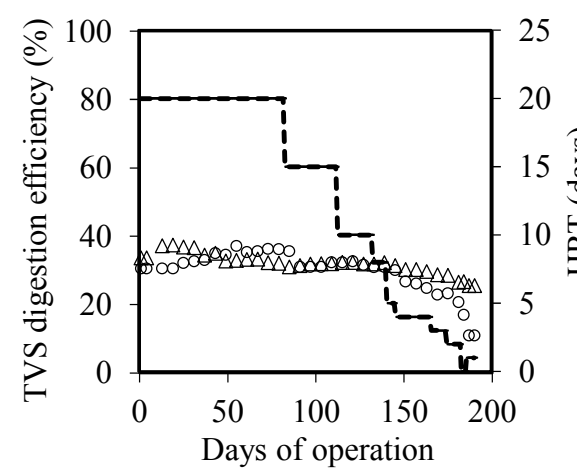

(a)

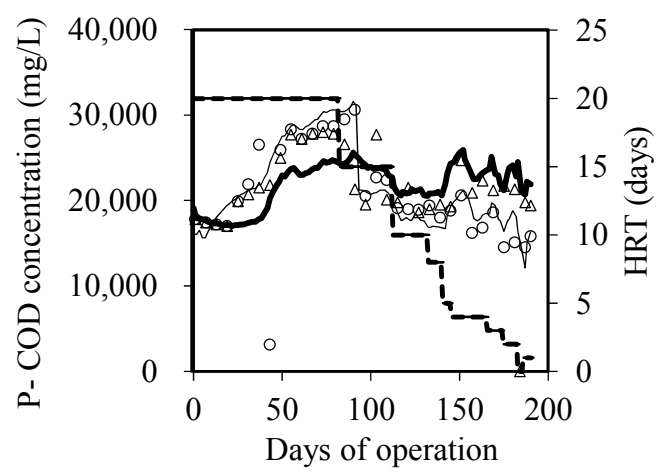

(b)

Fig. 4 - Digestion performances in the digesters (a): TVS digestion efficiency; (b): particulate COD concentration in the digesters (triangles: MD, circles: CD, dotted line: HRT, thin line: simulation of P-COD concentration)

\section{Soluble TOC and methane production rate}

As shown in Fig. 5, even at 5-day HRT the S-TOC in the MD was detected to be only around $300 \mathrm{mg} / \mathrm{L}$. On the other hand, in the CD the S-TOC concentration elevated to $3,000 \mathrm{mg} / \mathrm{L}$ suggesting a washout of the anaerobic microorganisms took place. When the HRT was further reduced to 2 days, the soluble fraction started decreasing. Perhaps this was due to the limited decay rate of microorganisms of WAS in the system producing small amount of soluble substrate in such short HRT (r5 at Table 2 and Table 3 ). The response of S-TOC concentration was also reasonably simulated. During this operation the MD could keep a reasonably low S-TOC. Based on the distinct responses, the specific decay rate of $\mathrm{X}_{\mathrm{OHO}}$ and the specific growth rate of $\mathrm{X}_{\mathrm{ACO}}$ were calibrated. The MPRs of the two digesters provided almost identical response until day 150 (until reduction of HRT to 5 days). Corresponding to the deterioration of digestion efficiency at the CD, the MPR decreased remarkably. On the other hand, the MPR at the MD showed very high MPR until 4-day HRT because the VLR was doubled comparing to that at 8-day HRT due to more feeding of the WAS. The MPR declined afterward when the HRT was changed to less than 3 days. The kinetic of the methanogen on the growth was estimated from the elevation/decrease of MPR and the change of S-TOC.

\section{Concentration of microorganisms in the digesters}

The calculated concentration of the microorganisms is summarized as shown in Fig. 6 ((a): heterotrophic biomass $\left(\mathrm{X}_{\mathrm{OHO}}\right),(\mathrm{b})$ : acidogens $\left(\mathrm{X}_{\mathrm{ACO}}\right)$ and $(\mathrm{c})$ : methanogens $\left.\left(\mathrm{X}_{\mathrm{MEO}}\right)\right)$ in the digesters. Higher $\mathrm{X}_{\mathrm{ACO}}$ and $\mathrm{X}_{\mathrm{MEO}}$ concentrations in the MD were obtained comparing to those of the $\mathrm{CD}$ while comparable concentration of $\mathrm{X}_{\mathrm{OHO}}$ in the digesters was recognized. This meant that the difference of the process performance for the two digesters could be attributed to the difference of active anaerobic biomass for the two digesters. According to the kinetic simulation, the concentration of $\mathrm{X}_{\mathrm{ACO}}$ decreased when the HRT was set at less than 8 days. Although most sludge in the CD was lost at day 92 because a mechanical problem of the experimental apparatus occurred and re-startup of $\mathrm{CD}$ was obliged, the unexpected event could be also reasonably simulated as the reduction of MPR in Fig. 5b, which was the consequence of 
anaerobic biomass concentrations in the digesters. At the very short HRT conditions $(<$ 4-day HRT) $\mathrm{X}_{\mathrm{MEO}}$ was not supposed to grow in the CD resulting in the discontinuation of methane fermentation. In contrast, methanogenic activity was still observed and simulated for the MD at such very short HRT.

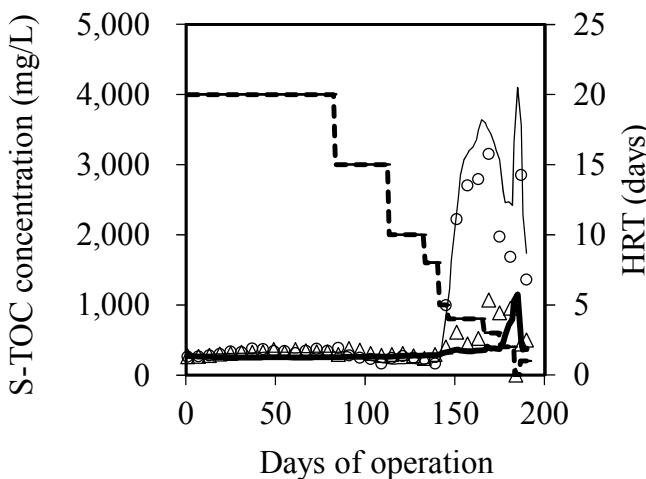

(a)

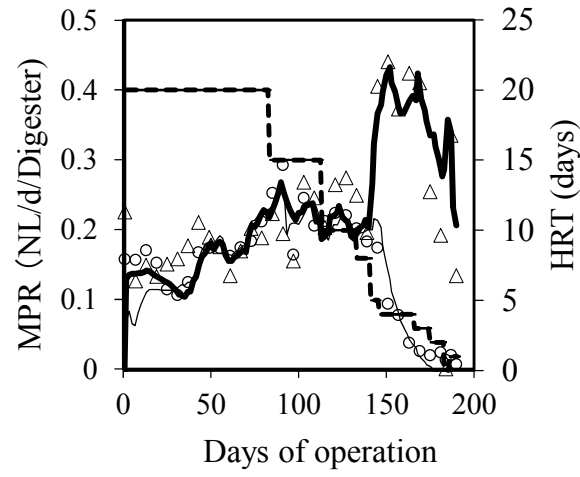

(b)

Fig. 5 - Production of soluble organics and methane gas in the digesters (a): S-TOC concentration; (b): Methane gas production rate (triangles: $\mathrm{MD}$, circles: $\mathrm{CD}$, dotted line: HRT, thin lines: simulation of S-TOC concentration and MPR).

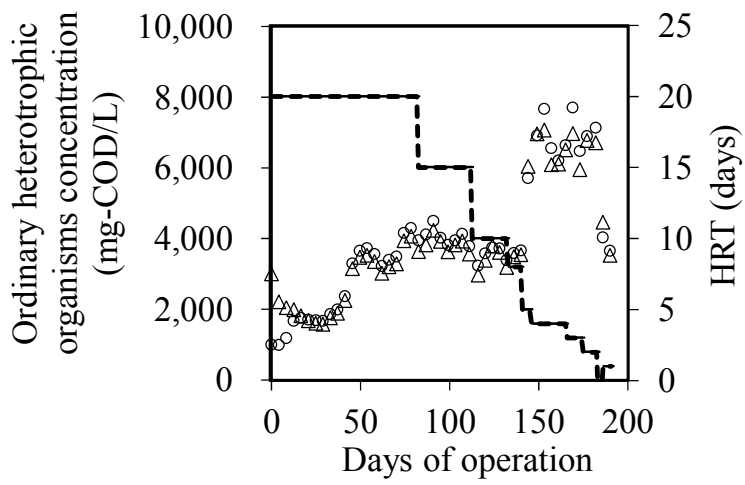

(a): Ordinary heterotrophs

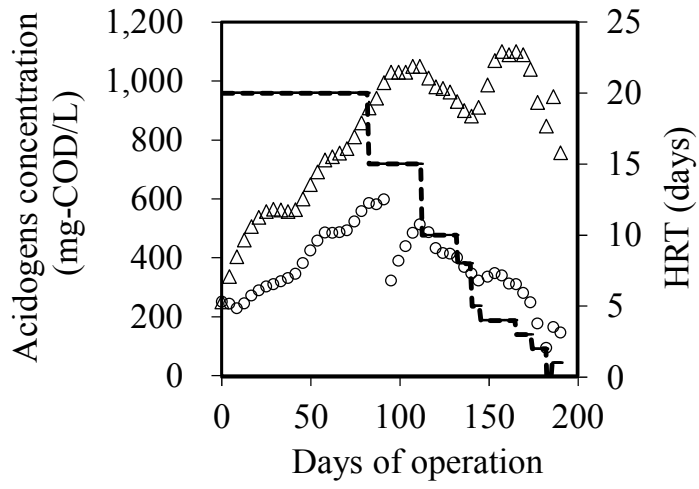

(b): Acidogens

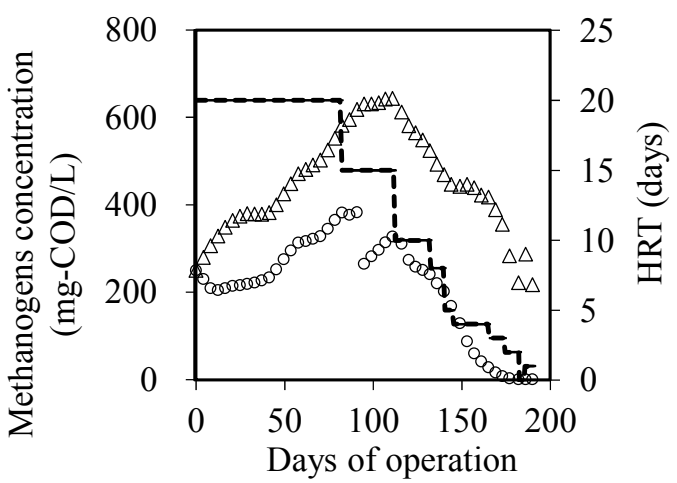

(c): Methanogens

Fig. 6 - Calculated concentration of microorganisms in the digesters (triangles: MD, circles: CD, dotted line: HRT). 
Table 3 - List of kinetics and stoichiometry of the anaerobic digestion process.

\begin{tabular}{|c|c|c|c|}
\hline Kinetics & This study & References & Unit \\
\hline $\begin{array}{l}\text { Maximum specific growth rate of } \\
\text { acidogens }\end{array}$ & 0.4 & $0.41-21^{1)}$ & $d^{-1}$ \\
\hline $\begin{array}{l}\text { Half-saturation coefficient on } \\
\text { growth of acidogens }\end{array}$ & 20 & $50-200^{1)}$ & $\mathrm{gCOD} / \mathrm{m}^{3}$ \\
\hline $\begin{array}{l}\text { Maximum specific growth rate of } \\
\text { methanogens }\end{array}$ & 0.17 & $0.02-8^{1)}$ & $d^{-1}$ \\
\hline $\begin{array}{l}\text { Half-saturation coefficient on } \\
\text { growth of methanogens }\end{array}$ & 30 & $\begin{array}{l}30-900^{1)} \\
\text { (acetate utilizer) }\end{array}$ & $\mathrm{gCOD} / \mathrm{m}^{3}$ \\
\hline Specific decay rate of methanogens & 0.01 & $\left.0.01-0.1^{1)}, 3\right)$ & $\mathrm{d}^{-1}$ \\
\hline $\begin{array}{l}\text { Specific anaerobic decay rate of } \\
\text { heterotrophs }\end{array}$ & 0.15 & $0.21^{4)}$ & $d^{-1}$ \\
\hline Stoichiometry & This study & References & Unit \\
\hline Production of acidogens & 0.08 & $0.08^{5)}$ & - \\
\hline Production of methanogens & 0.04 & $0.04^{5)}$ & - \\
\hline Production of inert materials & 0.08 & $0.08^{2)}$ & - \\
\hline
\end{tabular}

\section{Model calibration}

The COD concentration in the two digesters was used as composite variables to estimate the kinetics of individual microorganisms. The entrapped proportions of $\mathrm{X}_{\mathrm{ACO}}$ and $\mathrm{X}_{\mathrm{MEO}}$ that retained in the MD were calibrated to be $80 \%$ and $60 \%$ respectively. This suggested that the use of carrier media on the anaerobic digestion process would help the improvement of digestion performance by keeping the relevant active biomass for the decomposition of slowly degradable materials. The kinetic parameters obtained from the experiments are listed in Table 3, and the calibrated values were also compared with the default ones in ADM1 (Batstone et al., 2002), ASM1 (Henze et al., 2000), the anaerobic digestion of sewage sludge (Siegrist et al., 2002) and anaerobic decay of WAS (Yasui et al., 2006; Yasui et al., 2008). Although it appeared that slightly lower kinetics for $\mu_{\text {max_ACO }}, \mu_{\text {max_MEO, }} b_{\text {MEO }}$ and $b_{\text {OHO }}$ were obtained, in general, most of the kinetics were in the reasonable range even applying the simplified extended activated sludge model.

\section{CONCLUSION}

A simplified mathematical model was developed to simulate the moving-bed biofilm digester process in the dynamic condition. The calibrated coefficients used in the model allowed to reasonably simulate the experimental results. The results suggested that the biological activity of the microorganisms in the moving-bed biofilm digester could be sustained even in very short hydraulic retention time of below $4-5$ days. A clear improvement in TVS digestion efficiency and methane gas production rate were obtained when short plastic tubes were filled in the digester for the carrier material of biomass. Even though the conventional digester (without filling media) showed TVS digestion efficiency at only $10 \%$ during such critical HRT, 25\% of TVS digestion 
efficiency was achieved because the soluble organic intermediates from the decayed biomass was successfully decomposed by the anaerobic microorganisms entrapped in the moving-bed biofilm digester. This organic material was further degraded to methane gas.

\section{ACKNOWLEDGEMENT}

This research was supported by Grants-in-Aid for Scientific Research, JSPS, Japan, No. 25303006.

\section{REFERENCES}

APHA (2005) Standard Methods for the Examination of Water and Wastewater, $21^{\text {st }}$ ed., American Public Health Association, Washington DC, USA.

Appels L., Baeyens J., Degreve J. and Dewil R. (2008) Principles and potential of the anaerobic digestion of waste-activated sludge. Prog. Energy Combust. Sci., 34, 755-781.

Batstone D. J., Keller J., Angelidaki I., Kalyuzhnyi S. V., Pavlostathis S. G., Rozzi A., Sanders W. T. M., Siegrist H. and Vavilin V. A. (2002) Anaerobic digestion model No.1. (ADM1), IWA Scientific and Technical report No.13. IWA, London, UK.

Corominas L. I., Rieger L., Takacs I., Ekarna G., Hauduc H., Vanrolleghem P. A., Oehmen A., Gernaey K. V., van Loosdrecht M. C. M. and Comeau Y. (2010) New framework for standardized notation in wastewater treatment modelling. Water Sci. Technol., 61(4), 841-857.

Henze M., Gujer W., Mino T. and van Loosdrecht M. (2000) Activated Sludge Models ASM1, ASM2, ASM2D, ASM3, Scientific and Technical report No.9. IWA, London, UK.

Siegrist H., Vogt D., Garcia-Heras J. L. and Gujer W. (2002) Mathematical model for meso- and thermophilic anaerobic sewage sludge digestion. Environ. Sci. Technol., 36, 1113-1123.

Yasui H., Komatsu K., Goel R., Li Y. Y. and Noike T. (2008) Evaluation of state variable interface between the Activated Sludge Models and Anaerobic Digestion Model no 1. Water Sci. Technol., 57(6), 901-907.

Yasui H., Sugimoto M., Komatsu K., Goel R., Li Y. Y. and Noike T. (2006) An approach for substrate mapping between ASM and ADM1 for sludge digestion. Water Sci. Technol., 54(4), 83-92. 